\title{
CLINICAL PROFILE AND HISTOPATHOLOGICAL CORRELATION OF HANSEN'S DISEASE AMONG PATIENTS ATTENDING A PRIVATE MEDICAL COLLEGE HOSPITAL IN TAMILNADU- A RETROSPECTIVE STUDY
}

\author{
Rajalakshmi $R^{1}$, Balasubramanian $N^{2}$, Seethalakshmi R. S $S^{3}$
}

${ }^{1}$ Assistant Professor, Department of Dermatology, Chennai Medical College Hospital and Research Centre, Irungalur, Trichy, Tamilnadu. [The Tamilnadu Dr. M. G. R. Medical University, Chennai, Tamilnadu].

2Professor and HOD, Department of Dermatology, Chennai Medical College Hospital and Research Centre, Irungalur, Trichy, Tamilnadu. [The Tamilnadu Dr. M. G. R. Medical University, Chennai, Tamilnadu].

${ }^{3}$ Senior Resident, Department of Dermatology, Chennai Medical College Hospital and Research Centre, Irungalur, Trichy, Tamilnadu. [The Tamilnadu Dr. M. G. R. Medical University, Chennai, Tamilnadu].

\section{ABSTRACT}

\section{BACKGROUND}

Leprosy is a treatable chronic infectious disease, prevalent in South East Asian countries, especially India. Skin biopsy is an important tool in diagnosing leprosy and determining the type of leprosy. Before labelling a patient as a case of leprosy and starting multidrug treatment for particular type, the clinical findings should be correlated and confirmed with histopathological examination and bacteriological index of skin biopsy.

The objective of this study is to find out the clinical profile and histopathological correlation of Hansen's disease among patients attending a private medical college in Tamilnadu.

\section{MATERIALS AND METHODS}

A retrospective descriptive study was designed to collect clinical, bacteriological and histopathological details of leprosy patients from the case sheets and leprosy registers (from May 2010 to May 2017). The data pertaining to age, sex, clinical diagnosis, bacteriological index and histopathological diagnosis of leprosy, patients were tabulated in an Excel sheet and statistical analysis was done using SPSS V21.

\section{RESULTS}

In the present study, 113 untreated clinically diagnosed cases of leprosy were studied and analysed. There were 81 male patients and 32 female patients with age range from 9 years to 80 years. The most common clinical diagnosis was BT Hansen in 44 patients (38.9\%) followed by LL Hansen (34.5\%), BL Hansen (8.8\%), TT Hansen (7.1\%), BB Hansen (5.3\%), pure neuritic Hansen (2.7\%), histoid Hansen $(1.8 \%)$ and indeterminate Hansen in 1 patient $(0.9 \%)$. Slit skin smear was positive in $54.9 \%$ of patients and negative in $45.1 \%$ of patients. Considering the correlation between the clinical and histopathological diagnosis, maximum percentage of agreement (100\%) was seen in LL Hansen and the least level of agreement (11.11\%) was noted with indeterminate type of Hansen, i.e. cases were diagnosed more on histopathological examination rather than on clinical examination.

\section{CONCLUSION}

This study revealed that the histopathological examination along with bacteriological index should be carried out in all cases of leprosy to arrive at a definite diagnosis and also to classify the disease for appropriate multidrug therapy regimens.

\section{KEYWORDS}

Hansen's Disease, Clinical Diagnosis, Histopathological Diagnosis.

HOW TO CITE THIS ARTICLE: Rajalakshmi R, Balasubramanian N, Seethalakshmi RS. Clinical profile and histopathological correlation of Hansen's disease among patients attending a private medical college hospital in Tamilnadu- a retrospective study. J. Evolution Med. Dent. Sci. 2017;6(87):6040-6046, DOI: 10.14260/jemds/2017/1313

\section{BACKGROUND \\ Leprosy is a chronic infectious granulomatous disease caused by Mycobacterium leprae. It primarily affects the skin, peripheral nerves, upper respiratory tract and eyes. There is no other skin diseases, where the clinical manifestations are so varied as in leprosy.}

'Financial or Other Competing Interest': None.

Submission 25-09-2017, Peer Review 19-10-2017,

Acceptance 25-10-2017, Published 30-10-2017.

Corresponding Author:

Rajalakshmi R,

Assistant Professor,

Department of Dermatology,

Chennai Medical College Hospital and Research Centre,

Irungalur, Trichy, Tamilnadu-621105.

[The Tamilnadu Dr. M. G. R. Medical University,

Chennai, Tamilnadu]

E-mail: rajijipmer@yahoo.co.in

DOI: $10.14260 /$ jemds/2017/1313
The different clinical presentations of the disease are determined by the quality of host immune response. ${ }^{1}$ Although documented since antiquity, leprosy still continues to be one of the major public health problems in many countries including India. WHO currently uses a composite index for leprosy based on prevalence, new case detection, case detection rates, rates for grade 2 deformities (percentage and rate per million population) and percentage of child cases. As a result, 22 countries are now considered as having a "high burden for leprosy" (including high transmission): Angola, Bangladesh, Brazil, Comoros, Côte d'Ivoire, Democratic Republic of the Congo, Egypt, Ethiopia, Federated States of Micronesia, India, Indonesia, Kiribati, Madagascar, Mozambique, Myanmar, Nepal, Nigeria, Philippines, South Sudan, Sri Lanka, Sudan and United Republic of Tanzania. ${ }^{2}$

According to the WHO weekly epidemiological report 2015 , India reported $1,27,326$ new cases, accounting for $60 \%$ 
of the global new leprosy cases and the registered prevalence during 2015 was 86,028.

The prevalence of leprosy is gradually decreasing in many countries; however, rates of new case detection remain at almost the same level globally and in different regions. ${ }^{2}$ In India, since the inception of National Leprosy Eradication Programme (NLEP) in the year 1983, spectacular success have been made in reducing the burden of Leprosy. The country achieved the goal of leprosy elimination as a public health problem, i.e. prevalence rate (PR) of less than 1 case/ 10,000 population at National Level by December 2005, as set by National Health Policy 2002. Although prevalence has come down at national and state level, new cases are being continuously detected and these cases will have to be provided quality leprosy services. ${ }^{3}$

In Tamilnadu, during the year 1954 - 55, National Leprosy Eradication Programme (NLEP) was launched. The main objective of this scheme was to identify the cases early and cure them completely. The prevalence rate of the Leprosy in 1983 was 118 per 10,000 population. In 2005, the prevalence of leprosy declined to less than one per 10,000 population and the State achieved leprosy elimination status. The prevalence rate is 0.43 per 10,000 population as on February 2017.4

Accurate diagnosis and classification is of fundamental importance in leprosy, for correct and timely treatment of cases, epidemiological investigation, management and prevention of disabilities. Underdiagnosis as well as incorrect classification of the disease will also lead to continued transmission and increased morbidity of the disease. ${ }^{5}$ For this most of the times clinical diagnosis using the cardinal features (hypopigmented hypoaesthetic patches, peripheral nerve trunk thickening, demonstration of acid fast bacilli by SSS-slit skin smear examination) is adequate. But AFB positivity in SSS as well as histopathological examination of skin lesion is an important tool in accurate definitive diagnosis and classification of leprosy and it still remains the gold standard. The study of pathological changes in leprosy lesions has contributed a great deal to understanding of the disease and clinicopathological correlation studies have provided further insights into the disease, its varied manifestations and complications. Pathological examination helps to confirm a presumptive clinical diagnosis and also helps for exact typing.6,7 Hence, this study was undertaken to know the clinical profile of leprosy patients, bacteriological positivity and concordance between clinical and histopathological diagnosis among the cases of leprosy in this clinical setting.

\section{MATERIALS AND METHODS}

\section{Study Centre}

Department of Dermatology, Venereology and Leprology of Chennai Medical College Hospital and Research Centre, Trichy, Tamilnadu.

\section{Study Design}

Retrospective descriptive study.

\section{Sampling Method}

Convenient sampling.

\section{Study Population}

Patients attended the tertiary teaching hospital in and around Trichy, Tamilnadu.

\section{Sample Size}

113.

\section{Study Period}

May 2010 to May 2017.

\section{Methodology/Sampling}

Since this study is a retrospective study, the Medical Record Department of Chennai Medical College was visited and case sheets for the period of 7 years from May 2010 to May 2017 were segregated and 113 leprosy case sheets were separated. The case sheets were analysed and data such as date of visit, age, gender, clinical diagnosis, histopathological findings and slit skin smear reports were collected, tabulated and statistical analysis was done with SPSS V21.

\section{Sample Size Determination and Justification}

The sample size was determined by taking into account prevalence of Leprosy in India and Tamilnadu [0.68 per 10000 population in India and 0.38 per 10000 population in Tamilnadu]. Even though the sample size can be determined by prevalence rate of Leprosy, the very low prevalence resulted in very small sample size for the study. The convenience sample size was taken into account for sample size determination. The total leprosy cases detected for the period of May 2010 to May 2017 were taken as convenient sample for this study.

\section{Inclusion Criteria}

1. All new cases who attended this tertiary care teaching hospital during the study period without any prior medication and without features of lepra reactions were included.

2. All the clinically diagnosed new cases with slit skin smear reports and confirmed histopathological diagnosis were included (as per the records of Medical Record Department).

\section{Exclusion Criteria}

Patients who relapsed after MDT treatment and patients who presented with type 1 or type 2 lepra reactions at the time of diagnosis were excluded from the study as per the information available in the case in the Medical Record Department.

The details were tabulated in a Microsoft Excel sheet under the following headings: new cases by age, sex, history of contact with leprosy case, hypopigmented or erythematous skin lesions at the time of clinical diagnosis, clinical classification, slit skin smear positivity from the routine sites using Ziehl-Neelsen stain, histopathological diagnosis (Haematoxylin and Eosin- $\mathrm{H}$ and $\mathrm{E}$ and Fite-Faraco staining).

\section{Statistical Analysis}

Descriptive analysis was done by using SPSS Software v21.

\section{RESULTS}

In this study, a total of 113 new cases of leprosy over a period of 7 years from May 2010 to May 2017 were analysed. There 
were 81 male patients and 32 female patients with male-tofemale ratio of 2.53: 1 (Fig. 1). The age of the patients ranged from 9 years to 80 years. Maximum patients (23/113, 20.4\%) were in the age group between 51 and 60 years followed by 31 to 40 years (22/113) [Fig. 2]. The proportion of cases with age more than 50 years was $34.5 \%$. Out of 113 patients, 5 patients $(4.5 \%)$ were children aged less than 15 years. Positive contact history was present in 8 out of 113 patients (7.08\%). Three out of five childhood cases had history of contact with leprosy patients in their own family.

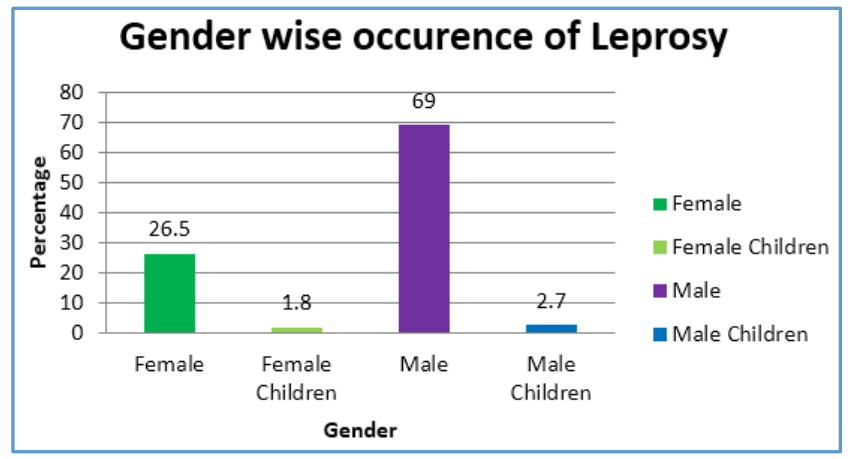

Figure 1. Gender Distribution

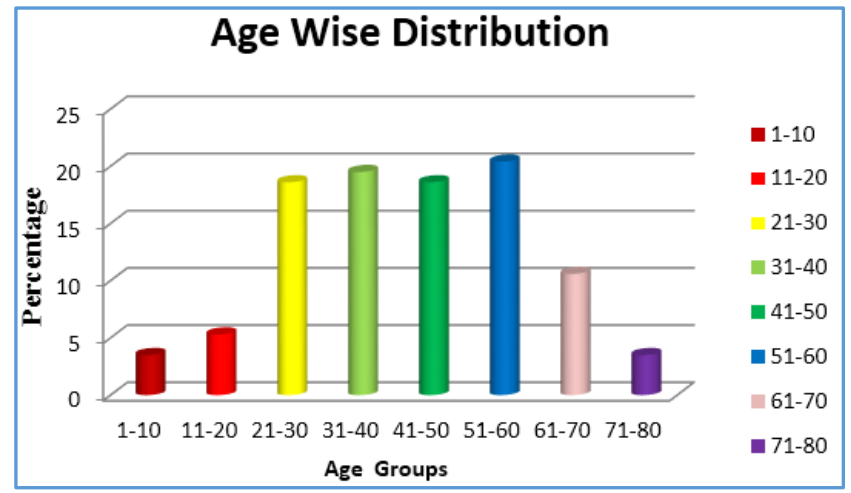

Figure 2. Age Distribution

Three out of 113 patients (3.5\%) had pure neuritic Hansen. Among the 110 patients with skin lesions, five patients had only single lesion (4.55\%). All except five patients $(95.45 \%)$ had more than one lesion at the time of presentation.

Majority of the patients (65 patients- 59.09\%) had hypopigmented skin lesions rather than erythematous lesions (45 patients- 40.91\%). Among the 65 patients who presented with hypopigmented patches, 34 patients (52.31\%) were towards tuberculoid pole of leprosy and 12 patients $(18.46 \%)$ were towards the lepromatous pole, whereas among the 45 patients with erythematous skin lesions 13 patients $(28.89 \%)$ were towards tuberculoid pole and 28 patients $(62.22 \%)$ were towards the tuberculoid pole of leprosy. None of the patients with indeterminate Hansen had erythematous lesions. Few of our patients had atypical lesions. One patient with lepromatous leprosy had pseudoainhum over the fifth toe of right foot. One patient with lepromatous leprosy had epistaxis due to pyogenic granuloma in the nasal cavity (Right side). Lesions over the palms were seen in 3 out of 113 patients.

Clinical diagnosis was BT Hansen in 44 patients (38.9\%), LL Hansen in 39 patients (34.5\%), BL Hansen in 10 patients
(8.8\%), TT Hansen in 8 patients $(7.1 \%)$, BB Hansen in 6 patients $(5.3 \%)$, pure neuritic Hansen in 3 patients $(2.7 \%)$, histoid Hansen in 2 patients (1.8\%), indeterminate Hansen in 1 patient $(0.9 \%)$ [Table 1 ].

\begin{tabular}{|c|c|c|}
\hline Clinical Diagnosis & No. of Patients & Percentage \\
\hline TT & 8 & 7.1 \\
\hline BT & 44 & 38.9 \\
\hline BB & 6 & 5.3 \\
\hline BL & 10 & 8.8 \\
\hline LL & 39 & 34.5 \\
\hline HH & 2 & 1.8 \\
\hline IL & 1 & 0.9 \\
\hline PN & 3 & $2.7 \%$ \\
\hline Total Patients & 113 & \\
\hline \multicolumn{2}{|c|}{ Table 1. Clinical Diagnosis } \\
\hline
\end{tabular}

Slit skin smear was positive in majority of the patients ( 62 patients- $54.9 \%$ multibacillary) and negative in 51 patients (45.1\% paucibacillary). Amongst the eight clinically diagnosed TT cases, only one case was AFB positive. Amongst the $44 \mathrm{BT}$ cases, five were positive. All the clinically diagnosed $B B$ cases except one were AFB positive. All the BL, LL cases were AFB positive. Categorising the bacteriological index status $11 / 113$ were $1+, 13 / 113$ were $2+, 17 / 113$ were $3+, 11 / 113$ were $4+, 6 / 113$ were $5+, 3 / 113$ were $6+$. Globi was seen in 1 patient with Histoid Hansen (Table 2).

\begin{tabular}{|c|c|c|}
\hline Bacteriological Index- SSS & No. of Patients & Percent \\
\hline $1+$ & 11 & 9.7 \\
\hline $2+$ & 13 & 11.5 \\
\hline $3+$ & 17 & 15.0 \\
\hline $4+$ & 11 & 9.7 \\
\hline $5+$ & 6 & 5.3 \\
\hline $6+$ & 3 & 2.7 \\
\hline Globi & 1 & .9 \\
\hline Neg & 51 & 45.1 \\
\hline Total & $\mathbf{1 1 3}$ & $\mathbf{1 0 0 . 0}$ \\
\hline \multicolumn{2}{|c}{} \\
\hline \multicolumn{2}{|c}{} \\
\hline
\end{tabular}

Out of 110 patients with skin lesions, histopathological diagnosis [Fig. 3] was BT Hansen (34 patients, 30.91\%), LL Hansen (26 patients, 23.64\%) patients, BL Hansen (14 patients, $12.72 \%$ ), TT Hansen (13 patients, $11.82 \%$ ), BB Hansen (12 patients, 10.91\%), indeterminate Hansen (9 patients, $8.18 \%$ ) and histoid Hansen (2 patients, $1.82 \%$ ). Histopathology was concordant with the clinical diagnosis in $65.45 \%$ of cases [Table 3].

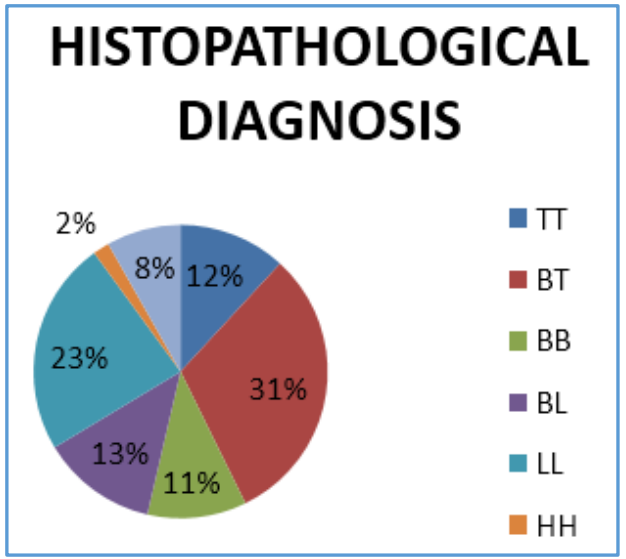

Figure 3. Histopathological Diagnosis 


\begin{tabular}{|c|c|c|}
\hline Concordant & 72 & $65.45 \%$ \\
\hline Non-concordant & 38 & $34.55 \%$ \\
\hline Total & $\mathbf{1 1 0}$ & \\
\hline \multicolumn{2}{|c|}{ Table 3. Histopathological Concordance } \\
\hline
\end{tabular}

Considering the correlation between the clinical and histopathological diagnosis maximum percentage of agreement $(100 \%)$ was seen in LL Hansen, where 26 cases were diagnosed clinically as LL Hansen and confirmed of LL type by histopathological examination. This was followed by BT type (percentage of agreement- 88\%), TT- 46.15\%, BL$28.57 \%$, BB- $25 \%$. The least level of agreement $(11.11 \%)$ was noted with indeterminate type of Hansen, i.e. cases were diagnosed more on histopathological examination rather than on clinical examination [Table 4].

\begin{tabular}{|c|c|c|c|c|c|c|c|c|}
\hline \multirow{2}{*}{ HPE DX } & \multicolumn{7}{|c|}{ Clinical Diagnosis } & \multirow{2}{*}{$\begin{array}{c}\% \text { of } \\
\text { Agreement }\end{array}$} \\
\hline & TT & BT & BB & BL & LL & HH & IL & \\
\hline TT (13) & 6 & 7 & - & - & - & - & - & $46.15 \%$ \\
\hline BT (34) & 1 & 30 & 2 & 1 & - & - & - & $88 \%$ \\
\hline $\mathrm{BB}(12)$ & - & 2 & 3 & 5 & 2 & - & - & $25 \%$ \\
\hline BL (14) & - & 1 & - & 4 & 9 & - & - & $28.57 \%$ \\
\hline LL (26) & - & - & - & - & 26 & - & - & $100 \%$ \\
\hline HH (2) & - & - & - & - & - & 2 & - & $100 \%$ \\
\hline IL (9) & 1 & 4 & 1 & - & 2 & - & 1 & 11.11 \\
\hline Total & 8 & 44 & 6 & 10 & 39 & 2 & 1 & \\
\hline & & & & & & & & tion \\
\hline
\end{tabular}

In this study, the histopathological concordance was maximum for LL and Histoid Hansen (100\%) and least for indeterminate type of leprosy (11.11\%), whereas clinical concordance was maximum for histoid Hansen and Indeterminate type of leprosy (100\%) and minimum for BL type of Hansen (40\%). Although almost similar distribution of cases was seen in clinical and histopathological classification, number of IL cases was more by histopathological classification than by clinical classification [Table 5].

\begin{tabular}{|c|c|c|}
\hline \multirow{2}{*}{ Classification } & \multicolumn{2}{|c|}{ Concordance of Diagnosis (Percentage) } \\
\cline { 2 - 3 } & $\begin{array}{c}\text { Correlated Cases/ } \\
\text { Histopathologically } \\
\text { Diagnosed Cases (\%) }\end{array}$ & $\begin{array}{c}\text { Correlated Cases/ } \\
\text { Clinically Diagnosed } \\
\text { Cases (\%) }\end{array}$ \\
\hline TT & 46.15 & 75 \\
\hline BT & 88 & 68 \\
\hline BB & 25 & 50 \\
\hline BL & 28.57 & 40 \\
\hline LL & 100 & 66.6 \\
\hline HH & 100 & 100 \\
\hline IL & 11.11 & 100 \\
\hline
\end{tabular}

Table 5. Concordance of Diagnosis of Leprosy by Two Modes of Examination- Clinical and Histopathological

\begin{tabular}{|c|c|c|c|c|c|c|c|}
\hline Parameters & Kakkad et al & Moorthy et al & Giridhar et al & Ramesh Bhat & Mathur et al & Thakkar, Patel & Our Study \\
\hline Male: female & $4.55: 1$ & $\begin{array}{c}242: 130 \\
(1.86: 1)\end{array}$ & $3.46: 1$ & $34: 21$ & $1.16: 1$ & $1.71: 1$ & $2.53: 1$ \\
\hline Childhood leprosy & $2(4 \%)$ & $6.45 \%$ & - & $7(15.22 \%)$ & $1(0.007 \%)$ & $12.3 \%$ & $5(4.5 \%)$ \\
\hline $\begin{array}{c}\text { Family or contact } \\
\text { H/O }\end{array}$ & - & - & - & $8(17.39 \%)$ & - & $21(8.3 \%)$ & $8(7.08 \%)$ \\
\hline Common age & $30-39$ yrs. & $20-29$ yrs. & $21-30$ yrs. & $36-50$ yrs. & $21-30$ yrs. & $17-40$ yrs. & $51-60$ yrs. \\
\hline $\begin{array}{c}\text { Most common } \\
\text { clinical type }\end{array}$ & BT (48\%) & BT (54.56\%) & BT (43/98) & BT (34.78\%) & TT (56/156) & BT (64.29\%) & BT (38.9\%) \\
\hline $\begin{array}{c}\text { Most common HPE } \\
\text { type }\end{array}$ & BT (40\%) & BT (72.31\%) & BT (42/98) & - & TT (41/156) & - & BT (30.1\%) \\
\hline Pure neuritic & - & - & - & $2.17 \%$ & & $18 \%$ & $3(3.5 \%)$ \\
\hline \multicolumn{7}{|c|}{ Table 6. Comparison of Clinical Profile with Other Studies } \\
\hline
\end{tabular}

\begin{tabular}{|c|c|c|c|c|}
\hline Study & Maximum Parity & Least Parity & Overall Parity & Maximum Parity at Polar Types Seen/ Not Seen \\
\hline Kakkad et al & TT (100\%) & BB (50\%) & $84 \%$ & No \\
\hline Giridhar et al & LL (93.75\%) & IL (27.78\%) & $60.23 \%$ & Yes \\
\hline Moorthy et al & LL (80\%) & IL (20\%) & $62.63 \%$ & No \\
\hline Pandya and Tailor & IL (87.5\%) & BB (0) & $58 \%$ & No \\
\hline Shivaswamy et al & LL (84.2\%) & BB, IL (50\%) & $74.7 \%$ & yes \\
\hline Bhushan et al & LL, TT (100\%) & BB (50\%) & $74.47 \%$ & Yes \\
\hline Mathur et al & LL (95.2\%) & BB (64.7\%) & $80.4 \%$ & Yes \\
\hline Kar et al & TT (87.5\%) & BL (53.8\%). & $70 \%$ & Yes \\
\hline Kalla et al & LL (76.7\%) & BB (37.0\%). & & No \\
\hline Our study & LL, Histoid (100\%) & IL (11.11\%) & $65.45 \%$ & Table 7. Comparison of Clinico-Histopathological Correlation with Other Studies \\
\hline \multicolumn{7}{|c|}{} \\
\hline
\end{tabular}

\section{DISCUSSION}

According to the WHO epidemiological report (September 2016), India, reported 127,326 new cases in 2015 accounting for $60 \%$ of the global new leprosy cases with a registered prevalence of 86028; new cases of MB leprosy was 65284: number of females 48808: no. of new cases in children was $11389 .{ }^{2}$ Currently, worldwide the prevalence rate of leprosy is on the decline. According to WHO, the prevalence rate of less than 1 case per 10000 is considered as elimination level. In India, the prevalence rate is 0.43 per 10,000 population as 
on February 2017. Globally, 38.8\% of new cases in 2015 were female. ${ }^{2}$

Leprosy manifests in different clinical and histopathological forms depending on the immune status of the host. There is no single gold standard method for the diagnosis of leprosy. Though, the clinical diagnosis is based on characteristic skin lesions with sensory loss, a great variation are seen in interpretation of these lesions, both clinically and histopathologically. ${ }^{8}$ Clinical classification gives recognition only to gross appearance of the lesion, whereas the parameters used for histopathological classification are well defined, precise and also take into account the immunological features.1,9 Before confirming a case of Leprosy of particular type, the clinical features should be correlated and confirmed with histological examination along with bacteriological index. ${ }^{10}$

The present study included 113 patients ranging from 9 years to 80 years with a male preponderance (Males: Females ratio 2.53: 1). This was similar to the results observed by Bhushan et al in 2008 (2.6: 1). ${ }^{11}$ However, Kakkad et al reported a male-to-female ratio of 4.55: 1.5 Although, many studies show that leprosy affects more men than women, there are exceptions such as in the study conducted by Gomes et al, where females outnumbered males. ${ }^{12}$ This small increase in the rates may be the result of an increase in the number of infected women or may be due to a more effective identification of these carriers. An improvement in the access of women to healthcare services and the fact that women are more concerned with their self-image than men could explain this increase in the identification of female cases. Otherwise, male preponderance indicates an increased vulnerability in males because of greater mobility and increased opportunities for contact in big population and also underdetection of female cases of leprosy. In our study, majority of the patients were in the age group of $51-60$ years. This was in contrast to the findings observed in other studies, where the common age group affected was up to 40 years. $5,10,13$

In our study childhood leprosy accounted for $4.4 \%$ of all cases, which was almost similar as observed by Kakkad et al (4\%). 5 However, Thakkar and Patel reported $12.3 \%$ of childhood cases; Bhat and Chaitra reported $15.22 \%$ of childhood cases. ${ }^{14,15}$ Positive family/ contact history was $7.08 \%$ in our study, which was comparable with the study of Kalla et al (9.5\%) and Thakkar and Patel (8.3\%), but $17.39 \%$ had a family or contact history of leprosy in the study by Bhat RM.14,15,16 Detection of childhood leprosy cases can be taken as an indicator of the greater severity of the endemic state of the disease. Amador et al reported that in children less than five years of age, leprosy may be potentially disabling due to the young age at which the disease was contracted and the possibility of deformities, although the occurrence of severe disabilities is uncommon in childhood. ${ }^{17}$ However, in our study, we did not come across any cases of leprosy in children less than 5 years of age.

In the present study, leprosy most commonly presents with hypopigmented macules or patches (65 patients$59.9 \%$ ). This was similar to the results of Giridhar et al, where hypopigmented lesions were commonly biopsied. ${ }^{10}$
In the present study, $54.9 \%$ cases were of multibacillary type and $45.1 \%$ cases were paucibacillary type. This was in contrast to the results observed in the study by Giridhar et al, where $74.52 \%$ cases were paucibacillary type and $24.48 \%$ were multibacillary type. This difference can be attributed to the regional variation and different socio-economic and immune status of the study population and also depict the changing trends in the leprosy. 10

In our study, the most common clinical diagnosis was BT Hansen in 44 patients (38.9\%), LL Hansen in 39 patients (34.5\%), BL Hansen in 10 patients (8.8\%), TT Hansen in 8 patients $(7.1 \%)$, BB Hansen in 6 patients $(5.3 \%)$, pure neuritic Hansen in 3 patients (2.7\%), histoid Hansen in 2 patients $(1.8 \%)$ and indeterminate Hansen in 1 patient (0.9\%). Similarly, BT Hansen was the most common type of Hansen clinically diagnosed in other studies (Table 6) by Giridhar et al, Shivaswamy et al, Bhat and Kakkad et al.5,9,10,15 But in the study by Mathur et al, TT Hansen was the commonest type diagnosed clinically in 56 out of 156 cases. ${ }^{18}$ Indeterminate leprosy was underdiagnosed on clinical examination and many of the cases have been diagnosed histopathologically.

After confirming the diagnosis by histopathological examination, the most common type of leprosy in our study was BT Hansen (34 patients, 30.91\%) followed by LL Hansen (26 patients, 23.64\%), BL Hansen (14 patients, 12.72\%), TT Hansen (13 patients, 11.82\%), BB Hansen (12 patients, $10.91 \%$ ), indeterminate Hansen ( 9 patients, $8.18 \%$ ) and histoid Hansen (2 patients, $1.82 \%$ ). This was comparable to the other studies by Giridhar et al, Moorthy et al and Kakkad et al where BT Hansen was the most common type.5,10,13 However, Kaur et al observed LL type of the disease to be the commonest type in their series and Mathur et al observed TT to be the most common in their series. ${ }^{18,19}$ This could be due to the different criteria used in selecting cases in the respective studies. Borderline group (BT, BB, BL) accounted for majority of the cases (53\%) in our study. This was similar to the findings observed in other studies by Kakkad et al, Shivaswamy et al, Kaur et al and Sharma et al.5,9,19,20 However, BL and LL Hansen together accounted for nearly half of the total cases in our study (49/113).

In the present study, complete parity between clinical type and histopathological type was noted in $65.45 \%$ of cases which was almost similar to the results of study by Moorthy et al (62.6\%). ${ }^{13}$ Varying results have been observed in other studies (Table 5) Kakkad (84\%), Giridhar et al (60.23\%), Kar et al (70\%) and Shivaswamy et al (74.7\%).5,9,10,21

Parity for individual type of leprosy in this study was highest for LL (100\%) and Histoid types (100\%) followed by BT (88\%), TT (46.15\%), BL (28.57\%), BB (25\%) and IL (11.11\%). Comparing with other studies (Table 7), Shivaswamy et al found that clinico-histological correlation was highest with LL (84.2\%) followed by BL (73.3\%), BT (64.1\%), TT (56\%) and 50 percent in BB and IL. ${ }^{9}$ In the study by Pandya and Taylor in 2008, parity for individual type of leprosy was highest for IL (87.7\%) followed by LL (83.3\%), TT (66.7\%), BT (53.3\%, BB (0) and BL (36.3\%).22 In the study by Giridhar et al, parity for individual type of leprosy was found to be TT (78.57\%), BT (73.81\%), BB (0\%), BL (87.5\%), LL (93.75\%) and IL (27.78\%). ${ }^{10}$ In a study by Moorthy et al, 
while correlating the histopathological diagnosis with clinical diagnosis, maximum correlation $(80 \%)$ was noted in LL patients followed by BL (70\%), BT (66.54\%), BB (50\%), TT $(46.15 \%)$ and it was very poor in IL $(20 \%) \cdot{ }^{13}$ Kar et al in their study observed total parity in $70 \%$. They also observed highest parity in stable poles, i.e. TT (87.5\%) and LL (71.4\%) followed by IL (81.2\%), BT (60.9\%), BB (54.5\%) and BL $(53.8 \%))^{21}$ Kalla et al in a study of 736 patients observed highest parity in LL and TT group (76.7\% and $75.6 \%)$ respectively, followed by BT (44.2\%), BL (43.7\%) and BB $(37.0 \%){ }^{16}$ Kar et al, Kalla et al and Mitra et al observed highest parity in stable poles, i.e. TT and LL.16,21,23 Though we noted a higher correlation one of the stable poles LL Hansen in our study, we could not find high correlation on the other pole of leprosy. i.e. TT Hansen. Correlation is supposed to be better at stable poles LL and TT probably related to clinical and histological stability of the disease. Various factors also influence the histopathological diagnosis such as differences in sample size, choosing the biopsy site, age of the lesion, immunological and treatment status of the patient at the time of biopsy. In our study, many cases of indeterminate Hansen were diagnosed histopathologically rather than clinically, which was similar to the results of Moorthy et al. IL is an early and transitory stage of leprosy found in persons whose immunological status is yet to be determined and it may progress to one of the other determinate forms of the disease. The IL type appears to be problematic due to the non-specific histology of their lesion. The diagnosis of IL also depends on many factors such as nature and depth of the biopsy, the quality of sections and number of sections examined.

Clinical diagnosis of early leprosy lesions offers difficulties even to experienced dermatologists and leprologists. A definitive diagnosis may be possible by histopathological examination. The other important point to be considered is interobserver variation, both clinically and histopathologically.

\section{CONCLUSION}

Considering the data of present study and other comparative studies we may state that maximum correlation is seen with LL, as it shows a fixed histopathology. However, in early cases of tuberculoid (TT) and indeterminate (IL) forms of disease, histopathology shows ambiguity. Thus, histopathology should be viewed in relation to clinical diagnosis as revealed in our study. Therefore, skin biopsies should be taken from the representative lesions in order to establish the diagnosis as an adjunct to clinical diagnosis and fulfilling the criteria for classifying the disease spectrum, which directly influences the proper treatment and eradication of the disease, we conclude from our study that histopathological examination along with bacteriological index should be carried out in all cases of leprosy to arrive at a definite diagnosis and also to classify the disease for appropriate multidrug therapy regimens.

\section{ACKNOWLEDGEMENT}

The authors gratefully acknowledge Mr. M. Ismail, Research Coordinator, Institutional Research Board, Chennai Medical College Hospital and Research Centre, Irungalur, Trichy,
Tamilnadu-621105, for the assistance rendered for the preparation of this original article.

\section{REFERENCES}

[1] Jopling WH, McDougall AC. Handbook of leprosy. $5^{\text {th }}$ edition. Delhi: CBS Publishers and Distributors 1996:10-53.

[2] WHO. Global leprosy update, 2015: time for action, accountability and inclusion. Weekly Epidemiological Report 2015;91(35):405-20.

[3] National Leprosy Eradication Programme (NLEP) annual report (2015 - 2016). Central Leprosy Division, Directorate General of Health Services, Ministry of Health and Family Welfare, Government of India, Nirman Bhawan, New Delhi - 110011.

[4] NLEP annual report-2017. National Health Mission Tamilnadu. Department of Health and Family Welfare.

[5] Kakkad K, Padhi T, Pradhan K, et al. A study of clinical, bacteriological \& histopathological correlation in leprosy cases attending a Government Medical College in Western Odisha: some observations. Indian J Lepr 2016;88:97-103.

[6] Chacko CJG. Role of histopathology in the early diagnosis of leprosy. Indian J Lepr 1993;65:23-7.

[7] Lucus SB, Ridley DS. The use of histopathology in leprosy diagnosis and research. Lepr Rev 1989;60(4):257-62.

[8] Mohan N, Mishra N. Clinico histopathological correlation within the spectrum of Hansen's disease: a multicentric study in North India. Int J Med Res \& Health Sci 2013;2(4):887-92.

[9] Shivaswamy KN, Shyamprasad AL, Sumathy TK, et al. Clinico histopathological correlation in leprosy. Dermatol Online J 2012;18(9):2.

[10] Giridhar M, Arora G, Lajpal K, et al. Clinicohistopathological concordance in leprosy - a clinical, histopathological and bacteriological study of 100 cases. Indian J Leprol 2012;84(3):217-25.

[11] Bhushan P, Sardana K, Koranne RV, et al. Diagnosing multibacillary leprosy: a comparative evaluation of diagnostic accuracy of slit-skin smear, bacterial index of granuloma and WHO operational classification. Indian J Dermatol Venereol Leprol 2008;74(4):322-6.

[12] Gomes CCD, Penna GO, Aires MAP, et al. Clinical and epidemiological profile of patients diagnosed with leprosy in a reference center in the northeast of Brazil Anais Brasileiros de Dermatologia 2005;80:S283-S8.

[13] Moorthy BN, Kumar P, Chatura KR, et al. Histopathological correlation of skin biopsies in leprosy. Indian J Dermatol Venereol Leprol 2001;67(6):299-301.

[14] Thakkar S, Patel SV. Clinical profile of leprosy patients: a prospective study. Indian J Dermatol 2014;59(2): 158-62.

[15] Bhat RM, Chaitra P. Profile of the new leprosy cases attending a South Indian Referral Hospital in 20112012. ISRN Tropical Medicine Article ID 579024, 2013;2013: p. 4. 
[16] Kalla G, Salodkar A, Kachhawa D. Clinical and histopathological correlation in leprosy. Int J Lepr Other Mycobact Dis 2000;68(2):184-5.

[17] Amador MPSC, Albuquerque PJB, Buna MIF, et al. Hanseníase na infância no município de Curionópolis Sudeste do Pará - relato de caso. Hansen Int 2011;26(2):121-5.

[18] Mathur MC, Ghimire RBK, Shrestha P, et al. Clinicohistopathological correlation in leprosy. Kathmandu Univ Med J (KUMJ) 2011;9(36):248-51.

[19] Kaur I, Indira D, Dogra S, et al. "Relatively spared zones" in leprosy: a clinicopathologicalstudy of 500 patients. Int J Lepr Other Mycobact Dis 2003;71(3):227-30.
[20] Sharma A, Sharma RK, Goswami KC, et al. Clinicohistopathological correlation in Leprosy. JK Science 2008;10(3):120-3.

[21] Kar PK, Arora PN, Ramasastry CV, et al. A Clinicopathological study of macular lesions in Leprosy. Indian J Lepr 1994;66(4):435-42.

[22] Pandya AN, Tailor HJ. Clinicohistopathological correlation of leprosy. Indian J Dermatol Venereol Leprol 2008;74(2):174-6.

[23] Mitra K, Biswas S, Saha B, et al. Correlation between clinical and histopathological criteria for the classification of leprosy. Indian J Dermatol 2001;46:135-7. 